\title{
O ARQUIVO LITERÁRIO DE ADELINO MAGALHÃES: MUITAS POSSIBILIDADES
}

\author{
Stela de Castro BICHUETTE \\ Universidade Estadual do Centro-Oeste \\ stelabichuette@yahoo.com.br
}

Resumo: O objetivo desse trabalho é apresentar para a comunidade acadêmica o arquivo literário inédito do escritor Adelino Magalhães (1887-1969), de posse de sua família desde a sua morte.

Palavras-chave: Adelino Magalhães. Arquivo literário. "Vesperais literárias".

\begin{abstract}
The aim of this work is to bring to light in the academic community the unpublished archives by writer Adelino Magalhães (1887-1969), which has been under his family's possession since his death.
\end{abstract}

Keywords: Adelino Magalhães. Literary archive. "Vesperais literárias".

\section{A materialidade do arquivo}

O arquivo de Adelino Magalhães (1887-1969) é composto por grandes cadernos com recortes de jornais, anotações a lápis, fotografias, algumas correspondências entre ele e seus companheiros ou entre ele e seus familiares. Arquivados em sacos plásticos, os cadernos-arquivos de Adelino Magalhães apresentam-se em estado muito avançado de decomposição, com muitas folhas soltas que se esfarelam ao serem manuseadas. Portanto, há urgência para que esse material seja restaurado e colocado à disposição de pesquisadores interessados na vida intelectual, política e literária dos primeiros anos do século XX.

À primeira vista, o arquivo não difere de um amontoado de cadernos velhos, amarelados e gastos. Ao se familiarizar com ele, passa-se a perceber que muitas informações relevantes estão lá, mas é necessário localizá-las, pois há uma enorme miscelânea, que inclui desde folhas rabiscadas até recortes de jornais e fotografias, quase tudo sem data, que Adelino Magalhães achou interessante guardar. O arquivo não se encontrava organizado, catalogado e pronto para ser explorado. Foi necessário fazer

\begin{tabular}{|l|l|l|l|l|}
\hline Pensares em Revista & São Gonçalo, RJ & n. 1 & $155-168$ & jul.-dez. 2012 \\
\hline
\end{tabular}


vários recortes, encontrar formas de organizar de uma maneira mais eficiente o material a ser trabalhado.

Assim, o trabalho com o arquivo literário, ao mesmo tempo em que encanta pelas inúmeras possibilidades de pesquisa e descobertas, amedronta pelos motivos inversos: a impossibilidade de dar ao arquivo o significado ou o tratamento adequado para que se possa tirar dele respostas tão bem guardadas durante tantos anos. Nesse sentido, os cadernos-arquivos abertos sobre uma escrivaninha no escritório do filho de Adelino Magalhães, cuja importância parece que só os anos são capazes de atribuir-lhes, guardam, escondidas, inúmeras possibilidades de revelação de um passado a ser redescoberto, de ressurgimento de pessoas esquecidas, de conhecimento encoberto pelo tempo. $\mathrm{O}$ arquivo de Adelino Magalhães esconde dois grandes projetos do autor: as "Vesperais Literárias" e o "Centro de Cultura Brasileira" (C.C.B).

Diante do arquivo de Adelino Magalhães, é claramente visível tanto o esquecimento do escritor quanto o de sua obra. $\mathrm{O}$ arquivo ficou por quase cinco décadas guardado na instância particular, mantido pela família do escritor. $\mathrm{O}$ fato de o arquivo de Adelino Magalhães ter ficado por quase cinco décadas guardado com a família pode ter contribuído para o esquecimento, tanto do escritor quanto do seu papel na vida literária do Rio de Janeiro. O arquivo, mantido na esfera do privado, impede que se desperte o interesse de pesquisadores.

\section{Certezas e dúvidas: o trabalho com o arquivo literário}

O estudo dos arquivos literários é algo que fascina pelas inúmeras possibilidades de pesquisa. É como se fosse uma longa viagem no tempo durante a qual vão surgindo documentos, cartas e fotografias permitindo ao pesquisador criar com o escritor uma intimidade. No caso do arquivo de Adelino Magalhães, aos meus olhos, ele se tornou ainda mais interessante, pois fui guiada pelo seu próprio filho que me mostrou outras particularidades além dos cadernos-arquivos organizados por seu pai.

Nas visitas à casa do Dr. Luiz Augusto Magalhães, sempre acompanhado de sua atenciosa e prestativa mulher, me foi mostrada a escrivaninha utilizada por Adelino Magalhães no "Grão Turco". Pude ver enquadrado o cardápio do almoço comemorativo, onde os pratos que foram servidos ganharam cada um o nome dos

\begin{tabular}{|l|l|l|l|l|}
\hline Pensares em Revista & São Gonçalo, RJ & n. 1 & $155-168$ & jul.-dez. 2012 \\
\hline
\end{tabular}


contos do escritor. O almoço foi oferecido por diversos amigos e realizou-se no restaurante Silvestre, no Rio de Janeiro. Assisti a vídeos familiares e íntimos, nos quais o escritor, já velho, aparece bem à vontade com suas netas. Somente depois dessa viagem maravilhosa, fui levada ao valioso arquivo de uma época tão distante.

Um estudo importantíssimo no campo dos estudos sobre o arquivo é Mal de arquivo: uma impressão freudiana, de Jacques Derrida, de 1995. No estudo, o filósofo discute a questão da psicanálise e seu possível vínculo com o judaísmo. No entanto, antes de entrar no seu objetivo específico, Derrida discute o conceito de arquivo, ou até mesmo, se há realmente um conceito único de arquivo.

Derrida explica que, antes de conceituar arquivo, é necessário entender qual o significado primeiro dessa palavra, do grego, Arkhê, significa ao mesmo tempo começo e comando. É desses dois significados que são gerados dois princípios: ontológico e nomológico, a saber:

Este nome coordena dois princípios em um: o princípio da natureza ou da história, ali onde as coisas começam - princípio físico, histórico ou ontológico -, mas também o princípio da lei ali onde os homens e os deuses comandam, ali onde se exerce a autoridade, a ordem social, nesse lugar a partir do qual a ordem é dada - princípio nomológico (DERRIDA, 2001, p. 11). (Grifos do autor).

Apesar da aparente comodidade oferecida pela reflexão acima, Derrida a desfaz ao afirmar que há sempre mais de um princípio tanto na ordem do começo como na ordem do comando, ou seja, "o conceito de arquivo abriga em si mesmo esta memória do nome arkhê. Mas também se conserva no abrigo desta memória que ele abriga: é o mesmo que dizer que a esquece" (DERRIDA, 2001, p. 12).

Então, de acordo com Derrida, o arquivo vem do arkheîon grego, que, originalmente, era uma casa, um domicílio, a residência dos magistrados superiores, chamados de arcontes, aqueles que comandavam. Aos arcontes era reconhecido o direito de fazer ou representar a lei. Dessa forma, na casa dos arcontes, autoridades publicamente reconhecidas, eram depositados os documentos oficiais, cabendo a eles não só guardá-los e zelar por sua segurança como também cabia-lhes a competência hermenêutica (DERRIDA, 2001, p. 12-13).

\begin{tabular}{|l|l|l|l|l|}
\hline Pensares em Revista & São Gonçalo, RJ & n. 1 & $155-168$ & jul.-dez. 2012 \\
\hline
\end{tabular}


Assim, eram necessários um guardião e uma localização, uma vez que para esses documentos ou arquivos deveria haver um suporte e uma residência. É daí que vem a ideia de domiciliação, que Derrida entende como local de depósito consensual dos documentos, marcando assim a passagem institucional do privado para o público.

Os documentos, que não são sempre escritos discursivos, não são guardados e classificados no arquivo senão em virtude de uma topologia privilegiada. Habitam este lugar particular, este lugar de escolha onde a lei e a singularidade se cruzam no privilégio. No cruzamento do topológico e do nomológico, do lugar e da lei, do suporte e da autoridade, uma cena de domiciliação torna-se, ao mesmo tempo, visível e invisível (DERRIDA, 2001, p. 13).

Dessa forma, o poder do arconte vai além da função topo-nomológica; ele não requer somente o suporte estável e uma autoridade hermenêutica legítima. Há ainda a necessidade de outro, o poder de consignação, poder que deve estar junto ao poder arcôntico. Segundo Derrida, por consignação entende-se o ato de reunir os signos:

A consignação tende a coordenar um único corpus em um sistema ou uma sincronia na qual todos os elementos articulam a unidade de uma configuração. Num arquivo, não deve haver dissociações absoluta, heterogeneidade ou segredo que viesse a separar (secernere) compartimentar de modo absoluto. O princípio arcôntico do arquivo é também um princípio de consignação, isto é, de reunião (DERRIDA, 2001, p. 14). (Grifos do autor).

Em “Arquivar a própria vida”, Philippe Artières (1997) não explica o processo de arquivamento de acordo com o valor etimológico do sentido que está na palavra arquivo, como fez Derrida. Dentro de outra vertente, o autor explica que as práticas de se autoarquivar não são feitas apenas por escritores ou pessoas importantes. Para Artières, as pessoas, ou nós mesmos, ao arrumarmos nossos pertences, fazemos triagens guiadas por contraditórias e sucessivas intenções, assim "passam[os] o tempo a arquivar nossas vidas: arrumamos, desarrumamos, reclassificamos. Por meio dessas práticas minúsculas, construímos uma imagem, para nós mesmos e às vezes para os outros" (ARTIÈRES, 1997, p. 10).

Continuando suas reflexões, Artières (1997, p. 11) argumenta que as pessoas arquivam sua vida por várias razões, mas que:

\begin{tabular}{|l|l|l|l|l|}
\hline Pensares em Revista & São Gonçalo, RJ & n. 1 & $155-168$ & jul.-dez. 2012 \\
\hline
\end{tabular}


[...] não arquivamos nossas vidas, não pomos nossas vidas em conserva de qualquer maneira; não guardamos todas as maçãs de nossa cesta pessoal; fazemos um acordo com a realidade, manipulamos a existência: omitimos, rasuramos, riscamos, sublinhamos, damos destaque a certas passagens.

Essa ação de manipular o que seria preservado é a que encontramos nos arquivoscadernos de Adelino Magalhães. Ele faz as escolhas daquilo que achava importante para seu autoarquivamento. Entretanto, todas com o sentido de uma intenção autobiográfica. De outra forma, que propósito teria o exercício de arquivar? Assim,

[...] o caráter normativo e o processo de objetivação e de sujeição que poderiam aparecer a princípio, cedem na verdade o lugar a um movimento de subjetivação. Escrever um diário, guardar papéis, assim como escrever uma autobiografia, são práticas que participam mais daquilo que Foucault chamava a preocupação com o eu (ARTIÈRES, 1997, p. 11).

Nessa prática de construção de si mesmo, Artières propõe três aspectos dos arquivos do eu: a injunção social, a prática de arquivamento e a intenção autobiográfica. A injunção social seriam aqueles papéis que a sociedade exige que todos tenham arquivados: são os registros civis, comprovantes de natureza econômica, diplomas, comprovantes de residência. $\mathrm{O}$ outro aspecto se refere à prática do arquivamento na qual pode ser enquadrado um dos aspectos dos arquivos de Adelino Magalhães, pois nele o indivíduo não arquiva somente porque é pressionado pelas exigências sociais, mas porque quer preservar a memória. São os recortes de jornais sobre ele próprio e sobre seus amigos, as fotografias das "Vesperais Literárias", os artigos em revista escritos por ele e por outros que ele julga interessantes.

Assim, Adelino Magalhães, quando selecionou o que seria posto em seus cadernos-arquivos, também estabeleceu como gostaria de ser lembrado no futuro. Arquivar a própria vida é

[...] simbolicamente preparar o próprio processo: reunir as peças necessárias para a própria defesa, organizá-las para refutar a representação que os outros têm de nós. Arquivar a própria vida é desafiar a ordem das coisas: a justiça dos homens assim como o trabalho do tempo (ARTIÈRES, 1997, p. 31).

\begin{tabular}{|l|l|l|l|l|}
\hline Pensares em Revista & São Gonçalo, RJ & n. 1 & $155-168$ & jul.-dez. 2012 \\
\hline
\end{tabular}


A última forma do arquivamento do eu seria a escritura autobiográfica, a escrita sobre si mesmo. Nela cabem, de acordo com Artières (1997), não somente a escrita de diários ou testemunhos, mas também uma coleção que contasse uma história. Os cadernos de atas do C.C.B podem ser enquadrados nessa definição. Organizados cronologicamente, eles contam a história de uma determinada instituição em um determinado tempo e local.

Para que se arquiva? Quem está do outro lado do arquivo? O arquivamento visa um futuro leitor, quer autorizado ou não, e tem a função de driblar o tempo e a finitude do produtor do arquivo, pois "arquivar a própria vida é definitivamente uma maneira de publicar a própria vida, é escrever o livro da própria vida que sobreviverá ao tempo e à morte" (ARTIÈRE, 1997, p. 32).

Em um artigo que conta a história do seu trabalho científico frente ao Acervo de Escritores Sulinos, a pesquisadora Maria da Glória Bordini (2009) apresenta uma interessante discussão sobre o acervo literário, relacionando-o ao papel de sua organização, não só para os pesquisadores dos autores arquivados, mas também para a formação de pesquisadores nos cursos de Letras, bem como a importante contribuição dos acervos para a pesquisa em si mesma.

Bordini acredita que a atuação nos acervos proporciona um aporte significativo de estudos literários diferenciados em relação ao que vinha sendo feito e mobiliza "a opinião pública com exposições e programas televisivos, trazendo à tona obras e autores que já se encontram na penumbra das bibliotecas, com poucos leitores" (BORDINI, 2009, p. 45).

Para a autora, a investigação nos acervos literários oferece a possibilidade de novos modelos espistemológicos, ou seja, uma abordagem da literatura menos autoencerrada. Dessa forma, "a existência de fontes primárias como material de investigação exige que se estabeleçam interrelações entre as correntes teóricas, abrindo caminho para uma reflexão menos dependente" (BORDINI, 2009, p. 45).

De acordo com Bordini (2009, p. 46), esse tipo de abordagem ensimesmada do objeto literário, sem uma inter-relação persiste porque a

[...] maior parte dos trabalhos de pesquisa em literatura ainda é imanentista, fixada no texto em si e quando muito em seus intertextos,

\begin{tabular}{|l|l|l|l|l|}
\hline Pensares em Revista & São Gonçalo, RJ & n. 1 & $155-168$ & jul.-dez. 2012 \\
\hline
\end{tabular}


voltada para as "aventuras da linguagem", no dizer de Barthes. No pólo oposto, é historicista, presa à dialética entre história e obra, de acordo com a cartilha marxista. As bases documentais permitem outras possibilidades: a investigação da gênese das obras, de seu destino, das relações entre os processos materiais e os processos ideativos que cercam não só a obra mas toda a instituição literária. Reinventam a biografia e autobiografia, dão acesso às subjetividades produtoras e receptoras, fazem ponte com os Estudos Culturais, com as preocupações pós-modernas e pós-coloniais ligadas à construção de identidades e às lutas das minorias, desfazendo preconceitos.

Com toda essa gama de possibilidades disponibilizadas pela conservação e manutenção, o acervo literário abre-se para a pesquisa porque nele não há hierarquia; todos os dados presentes - falo agora especificamente do arquivo de Adelino Magalhães - vão do mais ínfimo cartão de "melhor marido" até um artigo perdido em revistas esquecidas. Os arquivos abrem possibilidades infinitas, é nesse sentido que os

[...] acervos não apenas proporcionam, como comumente se pensa, a comprovação de informações, diminuindo dúvidas históricas, mas geram possibilidades impensadas com o entrecruzamento de dados heterogêneos, que em geral ficam na periferia da crítica, do comparatismo e da teoria e que podem iluminar-lhes as atividades (BORDINI, 2004, p. 46).

No arquivo de Adelino Magalhães, um labirinto de folhas e papéis, marcados pela ação do tempo, pode ser percebida a amplitude de horizontes fecundos para a preservação da memória e da cultura, para o debate e para a investigação. Nesse sentido, ao remexer o arquivo literário, o despertador da memória adormecida, pressuponho revirar relações tensionais de poder, ou seja,

[...] que a memória se constitui como um campo de lutas políticas, em que se confrontam diferentes relatos da história, visando o controle do arquivo. Pensar o arquivo demanda, pois, uma atenta consideração das operações da memória e do esquecimento, de suas interconexões (MARQUES, 2007, p. 14).

É, portanto, legítimo dizer que o interesse pelos estudos dos arquivos torna-os, de acordo com Marques (2007, p. 14), “objetos de tratamento por parte dos saberes especializados". O fascínio pelo acervo do escritor dá-se justamente pelas possibilidades

\begin{tabular}{|l|l|l|l|l|}
\hline Pensares em Revista & São Gonçalo, RJ & n. 1 & $155-168$ & jul.-dez. 2012 \\
\hline
\end{tabular}


de entrar nos domínios do privado, o que aumenta o imaginário cultural e pode levar a pensar os arquivos como mediadores culturais, como figuras epistemológicas.

Ainda de acordo com o estudo de Marques, no Brasil, a instalação de centros de preservação dos nossos arquivos literários situa-se nas décadas de 70 e 80, marcadas, principalmente, "pela preocupação com os lugares da memória e, ao mesmo tempo, por forte pressão de mecanismos de amnésia social e histórica" (MARQUES, 2007, p. 18), visto serem os arquivos importantes para preservação e produção de conhecimento de nossa cultura e de nossa literatura. Ainda no referido artigo, Marques sugere que a importância de uma história dos arquivos literários no Brasil deve estar atenta às relações entre discurso e poder. Nesse sentido,

[...] uma história, enfim, ciente de que as origens estão rasuradas, perdidas, e que os acontecimentos somente nos são acessíveis pela mediação de documentos, em seus usos pelo poder. Trata-se, pois, de uma história efetiva construída a partir de um olhar micrológico, dotada de um caráter mais fragmentado, sem ambições totalizantes, como forma de se contrapor a uma história abstrata e idealista, evolutiva e teleológica (MARQUES, 2007, p. 18).

Observa-se então que, ao se entender a história da perspectiva colocada por Marques, estar-se-á mais bem preparado para examinar a multiplicidade de discursos ecoados dos acervos literários, pois assim poder-se-á ter a compreensão dos desafios que estão presentes no trabalho com eles, sem deixar de enfatizar que os arquivos estão marcados por dois termos: a política da memória, entendida como embates entre projetos culturais e sociais conflitantes, e o outro, sugerido e temido nas primeiras linhas deste trabalho, o do enfrentamento crítico do encanto com os arquivos, "cujas fontes documentais parecem nos prometer a verdade da obra de arte, fazendo-nos esquecer muitas vezes o caráter construído do documento, dos arquivos” (MARQUES, 2007, p. 18).

Sob a perspectiva de Marques (2007), na esteira de Derrida (2001), a noção de arquivo passa por aqueles dois princípios explicados pelo filósofo: o topológico e o nomológico. E de cunho mais significativo ainda é

[...] a passagem - de natureza complexa - do privado para o público, em que a casa do escritor torna-se um museu, um arquivo, aberto à comunidade. Ou em que seu acervo é confinado à guarda de uma 
instituição pública de seus arcontes, os guardiões dos arquivos universidade, centro de memória, de documentação, biblioteca, etc. (MARQUES, 2007, p. 19).

O problema do acervo literário encontrado e apontado no estudo de Marques consiste no fato de que os trabalhos com arquivo aumentam a crise do paradigma disciplinar moderno, "na medida em que problematizam categorias canônicas dos estudos literários, tais como: texto, obra, autor, valor estético universal, os saberes do arquivo tornam mais rarefeitos os fundamentos das disciplinas acadêmicas" (MARQUES, 2007, p. 19). Nesse sentido, os arquivos funcionam

[...] como forma de, ao narrativizar os arquivos literários, desconstruir a ordem original, a intencionalidade que os erigiu, operando outras análises e interpretações que afirmem novas possibilidades de articulação da nossa história cultural. Aliado a essa perspectiva, entendo que seria instigante também relacionar os arquivos literários ao conceito de sobrevida, a partir de Walter Benjamin e Jacques Derrida, na medida em que esses arquivos propiciam a sobrevivência cultural e literária, e sua interação com outros tempos, contextos, leitores (MARQUES, 2007, p. 20).

A montagem de uma história dos arquivos literários no Brasil possibilitará, na visão de Marques (2007, p. 21), examinar os impactos das atividades e pesquisas neles desenvolvidas, situar cada arquivo específico num contexto histórico mais amplo, estimular interesse por trabalhos e pesquisas com fontes primárias da literatura, proporcionar uma maior interação entre pessoas e instituições envolvidas na pesquisa em arquivos e museus literários.

A discussão acerca de uma história do arquivo literário, que Marques (2007) limita ao Brasil interessa, sobremaneira, pelo fato da sua proposta se basear na ideia de que há de se levar em conta a particularidade e a peculiaridade de cada arquivo em si. O acervo de Adelino Magalhães, entendido como instância de produção de discursos, pode ser questionado pelas perguntas sugeridas por Marques, em seu trabalho, quais sejam: Quem os profere? Que posições ocupam no seu circuito de transmissão? A partir de que lugares? Quais são as estratégias de enunciação? Que relações tais discursos estabelecem com outros discursos compondo uma rede discursiva? Dessa forma, a montagem de uma história dos arquivos literários no Brasil

\begin{tabular}{|l|l|l|l|l|}
\hline Pensares em Revista & São Gonçalo, RJ & n. 1 & $155-168$ & jul.-dez. 2012 \\
\hline
\end{tabular}


[...] supõe uma leitura atenta aos vazios, desvios e rupturas próprios da constituição desses espaços/textos em que se configura a memória literária e cultural do país. Comporta seja a problematização de conceitos basilares - como os de história, literatura, cânone, obra, valor literário, arquivo, etc. - seja a ampliação do estatuto da recepção crítica, porquanto o arquivo do escritor constitui-se num mundo em aberto, marcado pela precariedade e pelo transitório (MARQUES, 2007, p. 22).

A partir das pertinentes reflexões feitas por Marques acerca da construção da história do arquivo literário no Brasil, o arquivo de Adelino Magalhães pode transitar pela esfera daqueles arquivos a serem descobertos ou, como diz o referido pesquisador, o arquivo deixará o núcleo privado para se tornar objeto de pesquisa, sendo posto, assim, no âmbito do público. A pesquisa sobre o acervo do escritor pode recuperar parte da história do autor e de sua movimentação em torno de uma vida intelectual tão frenética no começo do século passado.

Para ajudar no trato do acervo de Adelino Magalhães são importantes também, as considerações feitas por Figueiredo (2007) sobre os cadernos autobiográficos de Lima Barreto. Os "Retalhos", como esses cadernos foram denominados pelo autor e depois publicados e organizados pelo seu biógrafo Francisco de Assis Barbosa, permitem muitas correlações entre literatura, história e memória.

O conjunto de cadernos feitos por Adelino Magalhães também implica a visão da realidade de forma fragmentada em que os sentidos devem ser construídos folha por folha. No caso do arquivo de Adelino Magalhães, as escolhas do que ele julgava que deveria ser registrado são, obviamente, subjetivas, isto é, só é recortado e guardado nos cadernos aquilo que o autor considera relevante: a escolha do que se quer guardar na memória é quase sempre subjetiva e pessoal. Como aponta Figueiredo (2007, p. 87), em "O arquivo e o olhar: da vida literária à rede de imagens culturais":

[...] tornar significativo um conjunto de registros fragmentários implica propor uma leitura do cotidiano e da história que, longe de uma descrição paulatina, linearizada e cronológica dos acontecimentos, recolhe os discursos, as promessas, mas também as confidências e o silêncio reticente que pode vir das esquinas, dos becos, da massa anônima. Quem fala - um intelectual - e de onde fala, tornam instigantes esses fragmentos em que predomina a observação, no lugar do senso prático da experiência de vida.

\begin{tabular}{|l|l|l|l|l|}
\hline Pensares em Revista & São Gonçalo, RJ & n. 1 & $155-168$ & jul.-dez. 2012 \\
\hline
\end{tabular}


$\mathrm{O}$ estudo dos arquivos literários tem crescido ultimamente, sobretudo com o reposicionamento da figura do autor no cenário cultural. O trabalho do pesquisador dos espólios navega em várias direções para, por exemplo, "reconstruir uma gênese textual, firmar uma edição crítica, propor uma teoria de recepção ou ainda formular uma pesquisa em círculos intelectuais e sociais" (RIOS, 2008, p.45) e com isso perceber o arquivo como passível de uma reserva da memória e da cultura. Nessa direção, Rios (2008, p. 46) argumenta que a função primordial do arquivo é a preservação de um patrimônio cultural.

Isso se efetivará nos cadernos de memórias do autor que, sob tutela de seus herdeiros, ajudam a mapear outras nuanças possíveis, não só do autor como também de um círculo de intelectuais que fizeram parte da vida literária carioca no começo do século XX, tais como essas redes de sociabilidade entre os intelectuais cariocas, a visão de nacionalismo do grupo de Adelino Magalhães, a produção intelectual do autor.

A história contada por esses cadernos aponta várias vertentes possíveis sobre o escritor Adelino Magalhães e seu meio intelectual. No entanto, alguns pontos mereceram maior destaque por parte do autor. São eles: a referência da crítica especializada sobre sua obra; as notícias das "Vesperais Literárias"; a repercussão do C.C.B.; e o embate entre o Modernismo do Rio de Janeiro e o de São Paulo. São esses vetores que mais fortemente apontam as preocupações de Adelino Magalhães percebidas através do que o próprio autor elegeu como prioritário para ser mantido em arquivo.

\section{As "Vesperais Literárias", de 1921}

As "Vesperais Literárias", de 1921, foram um conjunto de quatro encontros ocorridos aos sábados, na Biblioteca Nacional, nos quais se discutiam temas literários, faziam-se homenagens a autores mortos, declamavam-se poemas e havia uma parte dedicada a concertos musicais. Já o C.C.B, que funcionava no Centro Paulista, no Rio Janeiro, foi um desdobramento das "Vesperais Literárias", local onde, além das tardes literárias, discutia-se como nacionalizar o país por meio de um programa próprio.

\begin{tabular}{|l|l|l|l|l|}
\hline Pensares em Revista & São Gonçalo, RJ & n. 1 & $155-168$ & jul.-dez. 2012 \\
\hline
\end{tabular}


Adelino Magalhães e o grupo do C.C.B apostavam no nacionalismo da literatura brasileira e na exaltação de seus autores, sem com isso menosprezar o passado, que deveria ser fonte de orgulho, visto que a nação estava sendo construída, e os projetos nacionalistas e brasilianistas estavam em voga. Com o centenário da Independência se aproximando, nada seria mais propício, no pensamento de Adelino Magalhães, para a história da literatura pátria, do que lembrar os vultos que abriram o caminho para as novas revoluções que estavam acontecendo na literatura dos anos de 1920.

Com isso, na busca incessante pelo nacionalismo, nada mais apropriado que afastar-se de tudo que lembrasse o passado colonizado, que lembrasse Portugal e a Europa. Nas reflexões de Mário da Silva Brito (1974, p.138), o país nos anos de 1920 estava marcado pelo nacionalismo e mais, naquele momento, "existia uma revivência do mesmo sentimento que, no século anterior, gerara o romantismo e levara os nacionais a uma atitude antiportuguesa, jacobina até".

As "Vesperais Literárias" foram o gérmen criador do C.C.B e continuaram a se fazer presentes durante todo o tempo de vida da agremiação cultural. O C.C.B foi uma instituição literária e cultural, apesar de pouco conhecida atualmente, diferentemente do que aconteceu em sua época quando foi, até certo ponto, aclamada por fazer parte do conjunto de intelectuais cujo propósito era criar estratégias para a nacionalização do país, mesmo que muitas vezes de forma ingênua e até mesmo xenofóbica.

O interesse por esses dois projetos de Magalhães da década de 20 surge em razão de o escritor estar inserido num ambiente intelectual que movimentava a sociedade carioca da época com os debates sobre o Modernismo, as artes novas e a modernidade. É importante ressaltar que, no cenário específico dos anos de 1920, havia um projeto maior de nacionalização e de construção da identidade nacional.

Grande parte da intelectualidade carioca que fazia parte dos contatos de Adelino Magalhães tem ficado à margem nos estudos literários. Nomes como o do próprio Adelino Magalhães, Tasso da Silveira (1895-1968), Murillo Araújo (1894-1980), Raul Pederneiras (1874-1953), Raul de Leoni (1895-1926), entre outros, não figuram com frequência nas pesquisas recentes. Em uma busca no Banco de Teses do sítio da Coordenação de Aperfeiçoamento de Nível Superior (CAPES), observa-se que há um número muito pequeno de trabalhos sobre estes escritores. Sobre Adelino Magalhães, o Banco de Teses conta apenas com oito trabalhos entre os anos de 1990 e 2010. Sobre

\begin{tabular}{|l|l|l|l|l|}
\hline Pensares em Revista & São Gonçalo, RJ & n. 1 & $155-168$ & jul.-dez. 2012 \\
\hline
\end{tabular}


Nestor Vítor (1868-1932), grande amigo de Adelino Magalhães e participante das rodas literárias cariocas, há apenas 3 trabalhos entre 2004 e 2010. Sobre outro grande nome do círculo de amizade de Adelino Magalhães, Andrade Muricy (1895-1984), há também apenas 3 trabalhos, entre 1997 e 2005. Sobre Raul Pederneiras foram encontrados 2 trabalhos, um de 2000 e outro de 2007. Sobre Raul de Leoni um único trabalho do ano de 1997.

Sobre Adelino Magalhães, os trabalhos encontrados são em maior número se comparados aos dos nomes anteriores. No sítio da CAPES, constam sete trabalhos que têm o escritor como objeto. No entanto, em nenhum deles há a referência à participação no ambiente intelectual carioca nas duas primeiras décadas do século XX.

O C.C.B. e, antes dele, as "Vesperais Literárias" vinculam-se tanto aos diversos estudos referentes ao desenvolvimento das articulações sobre a vontade de uma nacionalidade brasileira quanto ao Modernismo carioca e seu projeto estético dentro do movimento modernista brasileiro, que teve vários focos em todo país.

\section{Referências bibliográficas:}

ARTIÈRES, Philippe. Arquivar a própria vida. Revista Estudos Históricos, Rio de Janeiro, v. 11, n. 21, p. 09-34, 1997.

BORDINI, Maria da Glória. Os acervos de escritores sulinos e a memória literária brasileira. Patrimônio e memória, São Paulo, UNESP, FCLAs-CEDAP, v. 4, n. 2, p. 43 62, jun. 2009. Disponível em: $<$ http://www.assis.unesp.br/cedap/patrimonio_e_memoria/patrimonio_e_memoria_v4.n 2/artigos/acervos_sulinos.pdf $>$.

BRITO, Mário da Silva. História do Modernismo Brasileiro: antecedentes da Semana de Arte Moderna. Rio de Janeiro: Civilização Brasileira, 1974.

DERRIDA, Jacques. Mal de arquivo: uma impressão freudiana. Rio de Janeiro: Relume-Dumará, 2001.

FIGUEIREDO, Carmem Lucia Negreiros de. O arquivo e o olhar: da vida literária à rede de imagens culturais. Matraga, Rio de Janeiro, v. 14, n. 21, jul.-dez. 2007, p. 85103. Disponível em: <http://www.pgletras.uerj.br/matraga>.

MARQUES, Reinaldo. O arquivo literário como figura epistemológica. Matraga, Rio de Janeiro, v. 14, jul.-dez. 2007, p. 13-23. Disponível em: <www.pgletras.uerj.br/matraga>.

\begin{tabular}{|l|l|l|l|l|}
\hline Pensares em Revista & São Gonçalo, RJ & n. 1 & $155-168$ & jul.-dez. 2012 \\
\hline
\end{tabular}


RIOS, Otavio. Pelos caminhos da memória: arquivo de escritores e recepção de textos literários. Revista Todas as Letras, São Paulo, v. 10, n. 1, p. 44-50, 2008. Disponível em: 〈www3.mackenzie.br/todasletras>.

Recebido em: 31 de julho de 2012 .

Aprovado em: 31 de outubro de 2012.

\section{Sobre a autora:}

Doutora em Letras - Estudos Literários (UEL / 2012) e Mestre em Letras - Estudos Literários (UEL/2006). Especialista em Literatura Brasileira ( UEL/2004). Atualmente é professora colaboradora da Universidade Estadual do Centro Oeste (UNICENTRO/ Guarapuava, PR). Integra o grupo de pesquisa "Interfaces Língua e Literatura". Desenvolve o projeto de pesquisa "O arquivo Literário de Adelino Magalhães".

\begin{tabular}{|l|l|l|l|l|}
\hline Pensares em Revista & São Gonçalo, RJ & n. 1 & $155-168$ & jul.-dez. 2012 \\
\hline
\end{tabular}

